\title{
ABEC MEETING: comunicação científica e gestão editorial
}

A Associação Brasileira de Editores Científicos (ABEC Brasil) tem promovido desde 2017, seu encontro internacional denominado "Abec Meeting", como forma de apoiar os editores científicos brasileiros em sua atuação no âmbito da comunicação científica e gestão editorial. Desde então, tem fomentado o intercâmbio de experiências entre editores e estudiosos, por meio de palestras, conferências, oficinas e de apresentação de trabalhos na sessão do Pôster por Minuto, no qual autores têm um minuto para sintetizar sua proposta em plenária.

Em 2019, no evento realizado em Fortaleza-CE, alinhado ao tema do ABEC Meeting "Editor's Challenges for Open Science", a ABEC Brasil inovou ao implementar a avaliação aberta das propostas enviadas alinhando o processo de revisão ao movimento da ciência aberta. Assim, ofereceu maior transparência às atividades de avaliação dos trabalhos submetidos, além de apresentar aos seus membros da associação uma experiência prática sobre essa modalidade de avaliação, com a publicação dos trabalhos e seus respectivos pareceres no site do evento ${ }^{1}$.

Desde 2018, a Ciência da Informação em Revista tem publicado os trabalhos aceitos e apresentados na sessão Poster por Minuto em seu formato de texto completo. Essa parceria tem sido profícua, dando a oportunidade aos participantes da sessão de publicar seus trabaIhos já avaliados positivamente pelo evento, mas agora em versão estendida.

Esse número especial contribui com a visibilidade das propostas apresentadas, evidenciando a relevância da ABEC Brasil no cenário editorial científico do Brasil. A edição conta com um artigo original, dois relatos de pesquisa e quatro relatos de experiências. $O$ artigo original, "Evolução histórica do Fator de Impacto (FI) na base Web of Science (WoS) dos periódicos do Brasil entre 2008 e 2018", dos autores Renata Seabra Domingues, Claudia Vilalva Cassaro, Lucilene Delazari Santos, Hélio Rubens Carvalho Nunes, Juliana Siani Simionato, Milton Shintaku, Rui Seabra Ferreira Junior e Benedito Barraviera, analisa a série histórica do Fator de Impacto $(\mathrm{FI})$ das revistas brasileiras indexadas pelo Web of Science entre os anos de 2008 e 2018, revelando evolução das revistas e considerando os cenários que contribuíram no desempenho dos periódicos no período analisado.

O primeiro relato de pesquisa "Gestão editorial de periódico científico de acesso aberto em consolidação: análise da Revista Latino-Americana em Avaliação do Ciclo de Vida (LALCA)", de André Luiz Appel, Larissa de Araújo Alves, Tiago Emmanuel Nunes Braga e Thiago Oliveira Rodrigues, analisa a experimentação de indicadores, ferramentas e metodologias de avaliação de desempenho para Revista Latino-Americana em Avaliação do Ciclo de Vida, a qual se encontra em estágio de consolidação. O "Desenvolvimento e Aplicação de Metodologia para a consolidação do Fórum de Editores e Comunicação Científica da UFF" de Sofia Albuquerque e Thaiane de Oliveira é discutido no segundo relato de pesquisa. As autoras registram as atividades e o processo de consolidação do Fórum de Editores e Comunica-

${ }^{1}$ Disponíveis em: <http://ocs.abecbrasil.org.br/index.php/abec-meeting/abec-meeting2019/schedConf/presentations > 
ção Científica (Foco) da Universidade Federal Fluminense, buscando compartilhar a experiência e metodologias adotadas para a construção de um espaço coletivo para promover a melhoria do impacto e da circulação científica dos periódicos da universidade.

Com vistas ao resgate histórico e orientação para lançar novas metas de qualificação do periódico que editam, as autoras Adrize Rutz Porto, Sidnéia Tessmer Casarin, Juliane Portella Ribeiro e Clarice Alves Bonow relatam a experiência da "Editoração científica da Journal of Nursing and Health". As autoras a caminhada retratam a caminhada do periódico na comunicação científica na área da saúde e enfermagem destacando alguns avanços e desafios. O segundo relato de experiência "REMAT e a gestão editorial de 2019: da ampliação de indexadores à publicação em fluxo contínuo" de Glauciane Klein Burgiert Padilha, Greice da Silva Lorenzzetti Andreis, Katia Arcaro e Daiane Scopel Boff relata a editoração científica por meio de um breve resgate histórico do periódico indicando as melhorias realizadas em 2019.

O relato de experiência "Os desafios enfrentados pela equipe editorial do Journal of Venomous Animals and Toxins including Tropical Diseases na transição entre dois publishers de renome internacional" de Claudia Vilalva Cassaro, Juliana Siani Simionato, Selma de Lourdes Pires Martins, José Claudio Pires Martins, Lucilene Delazari Santos, Rui Seabra Ferreira Junior e Benedito Barraviera retrata o esforço da equipe editorial no processo de transição da revista, de um publisher internacional para uma nacional, de forma a garantir o acesso aberto e a sustentabilidade do periódico. Encerrando o número, no relato de experiência "A Trilha de um periódico científico de uma instituição particular na transição da publicação impressa à eletrônica e na busca de indexações internacionais", de Emanuela Paula Martins, Márcia Thelma Rios Donato Marino e Juliana Maria de Sousa Pinto, temos um estudo de caso da Revista Tecnologia no qual as autoras discorrem sobre os desafios no processo de transição da publicação impressa à eletrônica do periódico e sua busca pela internacionalização.

Por fim, gostaria de agradecer à Ciência da Informação em Revista e seus editores pela oportunidade desta publicação com os artigos aceitos no ABEC Meeting 2019. Da mesma forma em que agradeço aos autores pela confiança. A todos o meu agradecimento e boa leitura.

\section{Rui Seabra Ferreira Junior}

Presidente da ABEC (2016-2020)

Presidente do ABEC Meeting 2019 